\title{
Carbamate-isocyanurate-bridged periodic mesoporous organosilica for van der Waals $\mathrm{CO}_{2}$ capture
}

Ali Zebardasti, ${ }^{\dagger}$ Mohammad G. Dekamin, ${ }^{\dagger}, *$ Esmail Doustkhah, ${ }^{\ddagger}, *$ M. Hussein N. Assadi ${ }^{\S}$

${ }^{\dagger}$ Department of Chemistry, Iran University of Science and Technology, Tehran, 1684613114, Iran.

E-mail:mdekamin@iust.ac.ir

International Center for Materials Nanoarchitechtonics, National Institute for Materials Science,

1-1 Namiki, Tsukuba, Ibaraki 305-0044, Japan.E-mail: Doustkhah.esmail@nims.go.jp

\$School of Materials Science and Engineering, UNSW Sydney, Sydney, NSW 2052, Australia.

Content

Title Page

Synthesis Schemes of THEIC Organosiloxane Bridge

Structural Characterization of THEIC Bridge

Materials Characterization

$\mathrm{CO}_{2}$ Tests Results

Density Functional Calculations

Experimental Section

Reference
Page

S1

S2

S3

S7

S8

$\mathrm{S} 10$

S12

S13 


\section{Synthesis Schemes of THEIC Organosiloxane Bridge}

Synthesis of THEIC bridge was performed by the solvent-free reaction of 1,3,5-tris(2hydroxythyl)isocyanurate (THEIC) with 3-(triethoxysilyl)propyl silane (IPTES) at melting temperature of THEIC (Scheme S1). This led to the synthesis of a new organosiloxane compound, which were characterized and identified by ${ }^{1} \mathrm{H}-\mathrm{NMR},{ }^{13} \mathrm{C}-\mathrm{NMR}$ (Figure S1), and mass spectroscopy (Figure S2). Synthesis of PMO-THEIC was achieved through a triblock copolymer, P123, as a soft template in acidic conditions in which the THEIC bridge and TEOS are hydrolyzing and co-condensing to form a sol-gel in the solution at $40^{\circ} \mathrm{C}$. The aging at 100 ${ }^{\circ} \mathrm{C}$ and subsequent treatment with $\mathrm{MeOH}$ led to the removal of the template (P123) from the pore channels. 


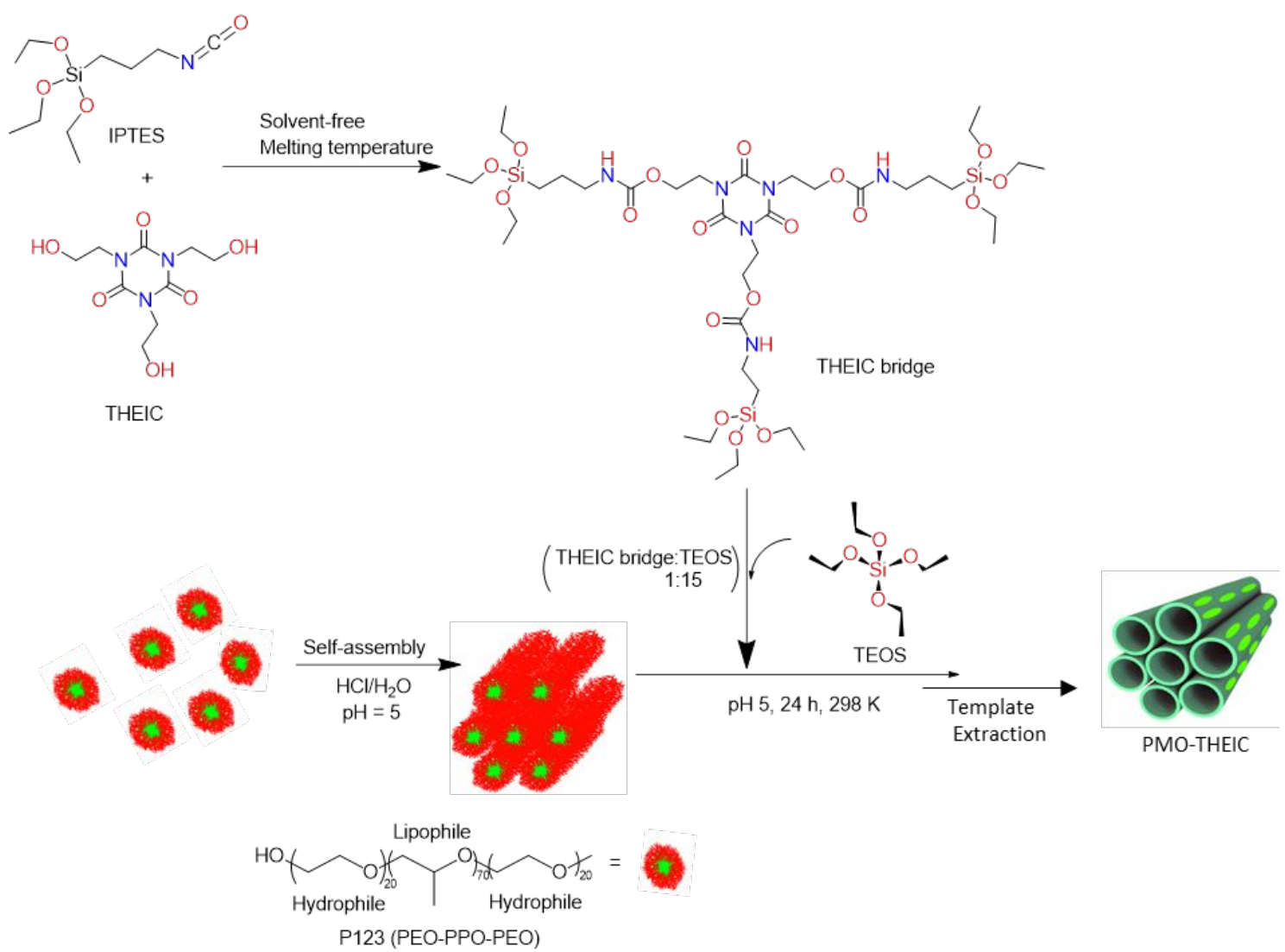

Scheme S1. Schematic illustration of THEIC organosiloxane bridge synthesis and the mechanism of PMO-THEIC formation in brief.

\section{Structural Characterization of THEIC Bridge}

Physical and spectral data of 1,3,5-tris(2-(3-(triethoxysilyl)propoxy)ethyl)-1,3,5-triazinane2,4,6-trione (THEIC bridge): Colorless liquid. ${ }^{1} \mathrm{H}-\mathrm{NMR}$ (300 MHz, DMSO-d $\left.\mathrm{d}_{6}\right): \delta 0.60$ (t, $J=$ $\left.8.1 \mathrm{~Hz}, \mathrm{CH}_{2}\right), 1.22\left(\mathrm{~m}, \mathrm{CH}_{3}\right), 1.61\left(\mathrm{~m}, \mathrm{CH}_{2}\right), 3.11\left(\mathrm{~m}, \mathrm{CH}_{2}\right), 3.80\left(\mathrm{q}, J=6.9 \mathrm{~Hz}, \mathrm{CH}_{2}\right), 4.16(\mathrm{~m}$, $\left.\mathrm{CH}_{2}\right), 4.28\left(\mathrm{~m}, \mathrm{CH}_{2}\right), 5.18$ (s, NH). ${ }^{13} \mathrm{C}-\mathrm{NMR}\left(75 \mathrm{MHz}, \mathrm{DMSO}-\mathrm{d}_{6}\right): \delta$ 7.55, 18.26, 23.25, 43.41, 46.50, 58.40, 61.05, 148.94, 156.23. MS (70 eV) $\mathrm{m} / \mathrm{z} 716\left(\mathrm{M}^{+}\right), 670,541,469,294,248$ 


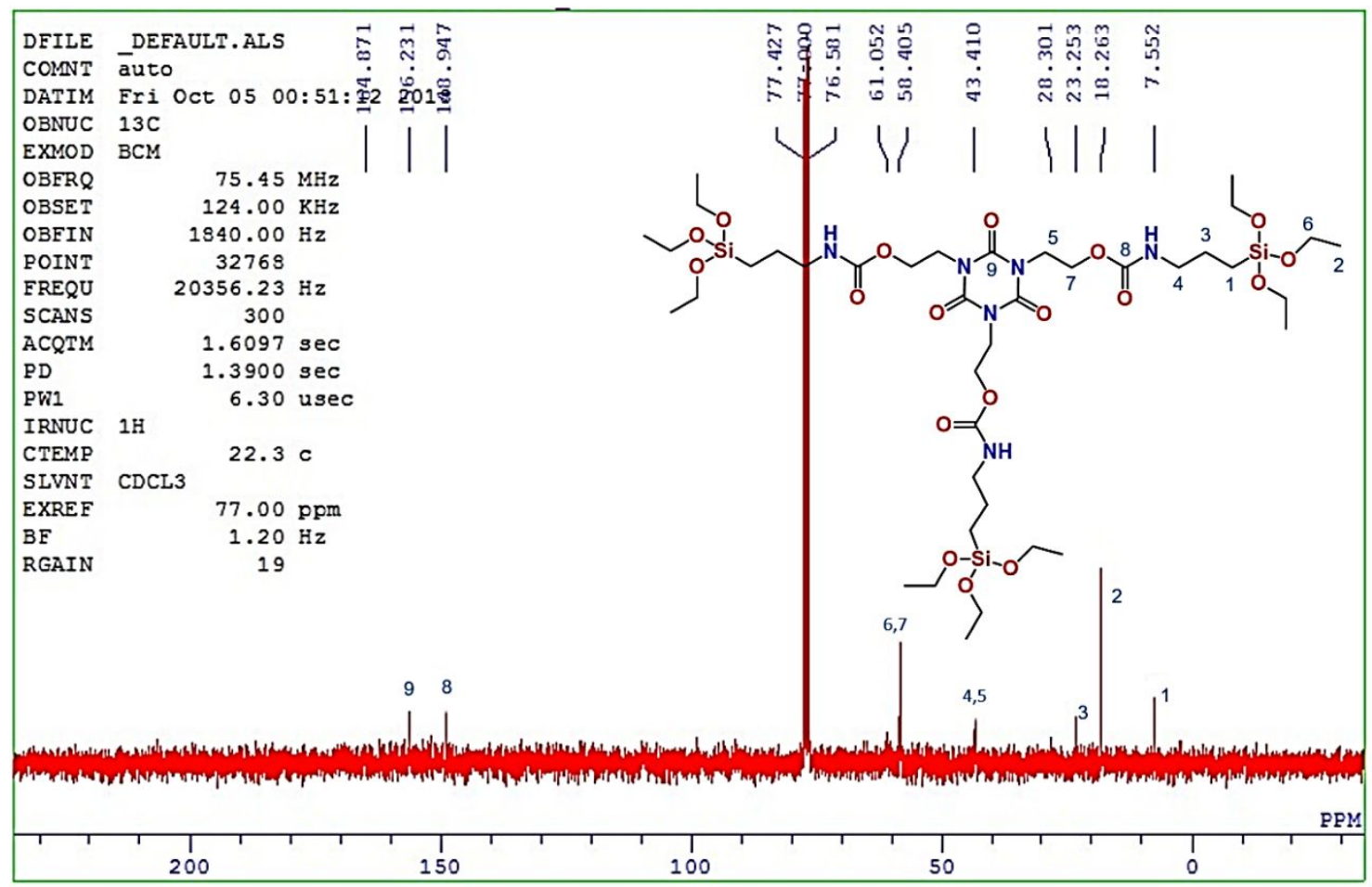

Figure S1. ${ }^{13} \mathrm{C}-\mathrm{NMR}$ spectra of THEIC bridge.

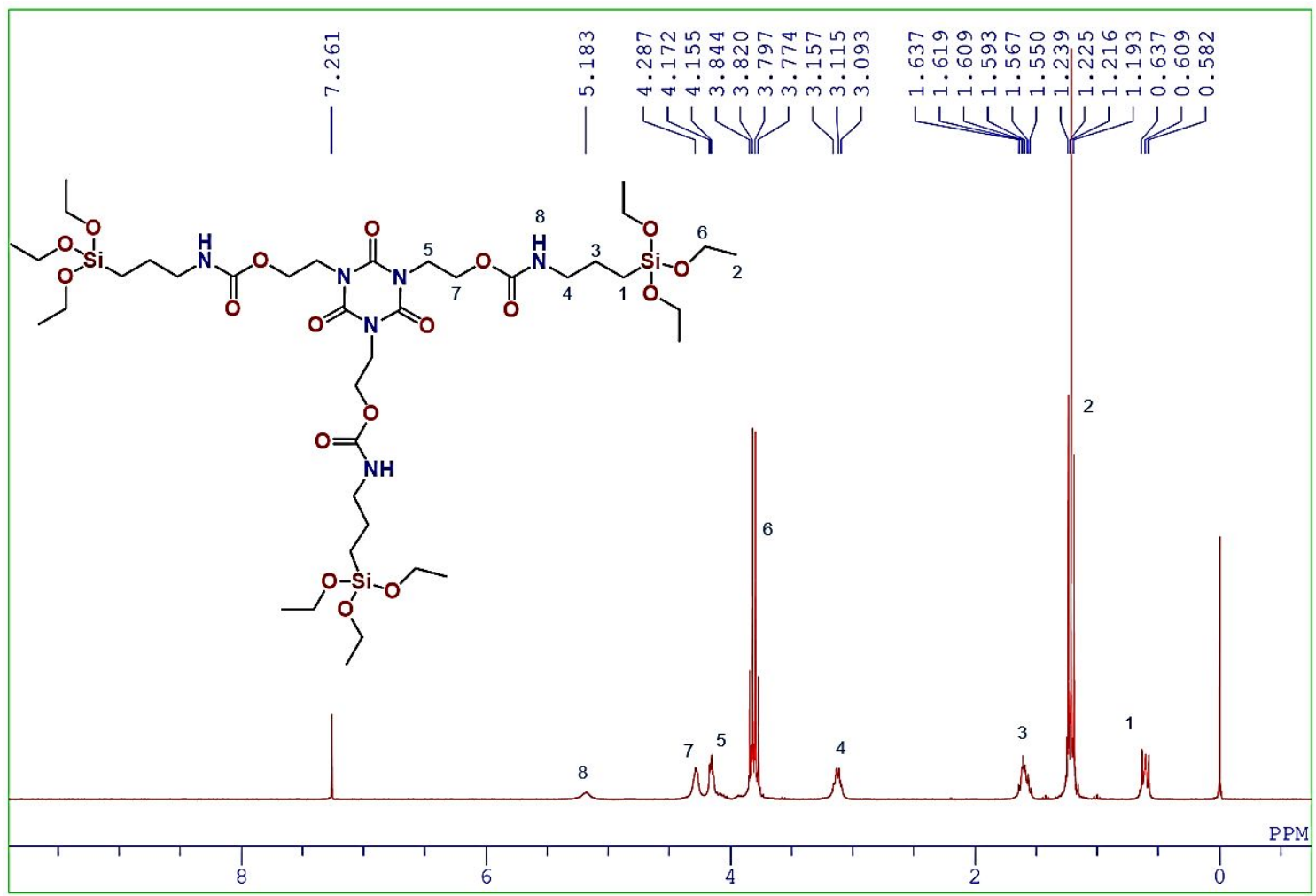

Figure S2. ${ }^{1} \mathrm{H}-\mathrm{NMR}$ spectra of THEIC bridge. 


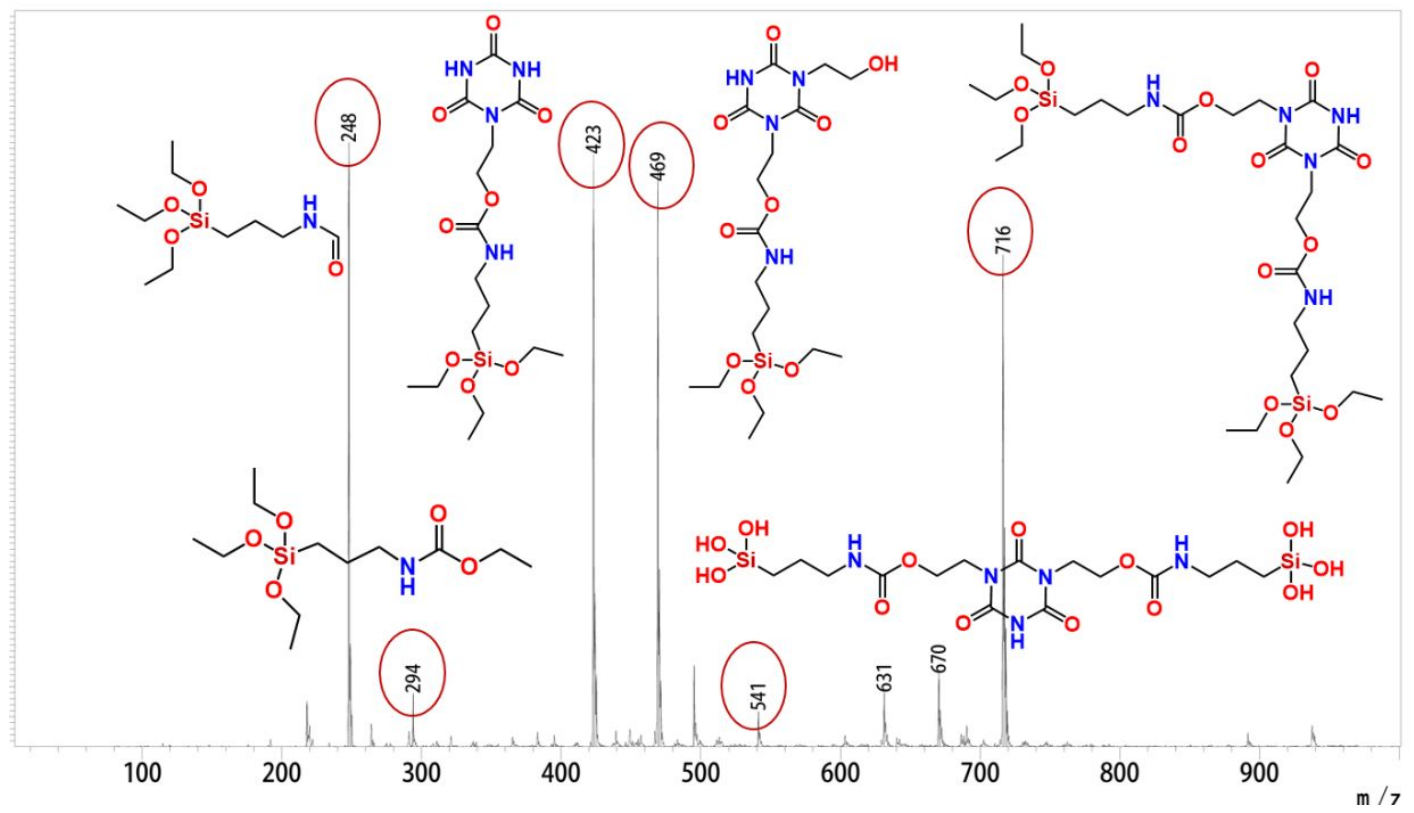

Figure S3. Mass spectrum of THEIC bridge.

Next, three different ratios of THEIC to TEOS (i.e., 1:3, 1:9, and 1:15, respectively) were used for the synthesis of PMO-THEIC. Then, the surface area for each obtained PMO was carefully examined. Accordingly, the molar ratio of 1:15 led to the highest surface area $\left(697 \mathrm{~m}^{2} \cdot \mathrm{g}^{-1}\right)$ when compared to other ratios (Figure S4). 


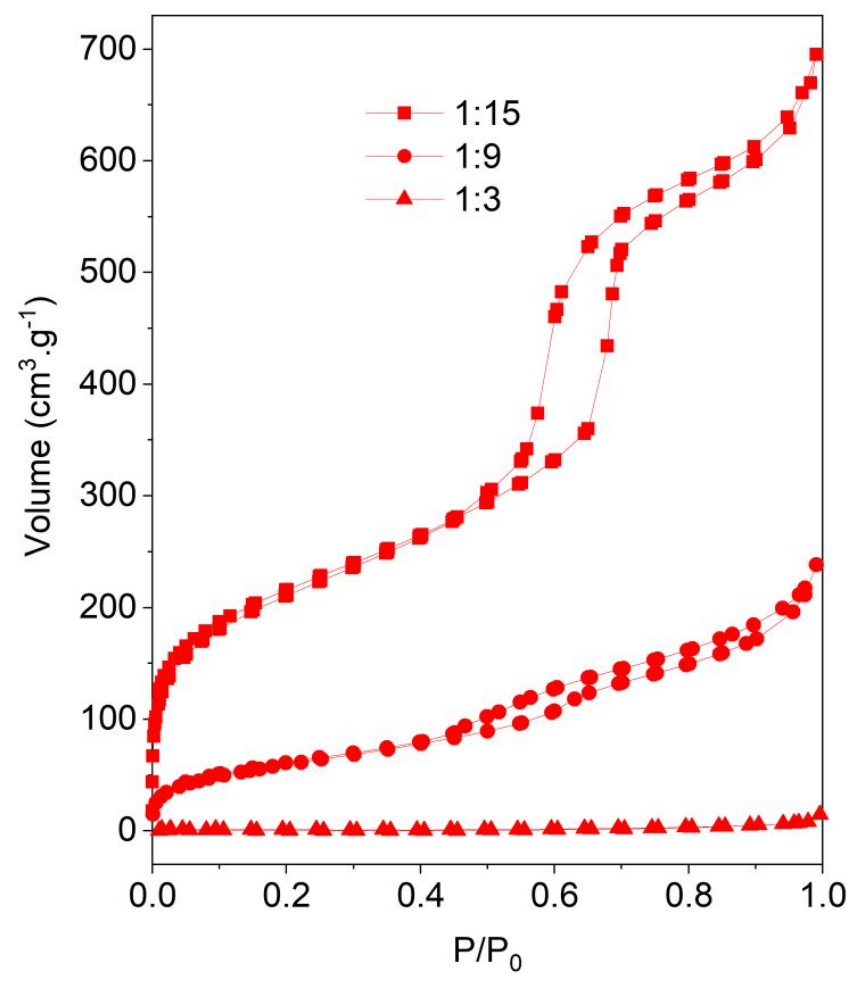

Figure S4. $\mathrm{N}_{2}$ adsorption-desorption isotherms of PMO-THEIC with three different molar ratios of THEIC bridge to TEOS, including 1:3, 1:9, and 1:15, respectively.

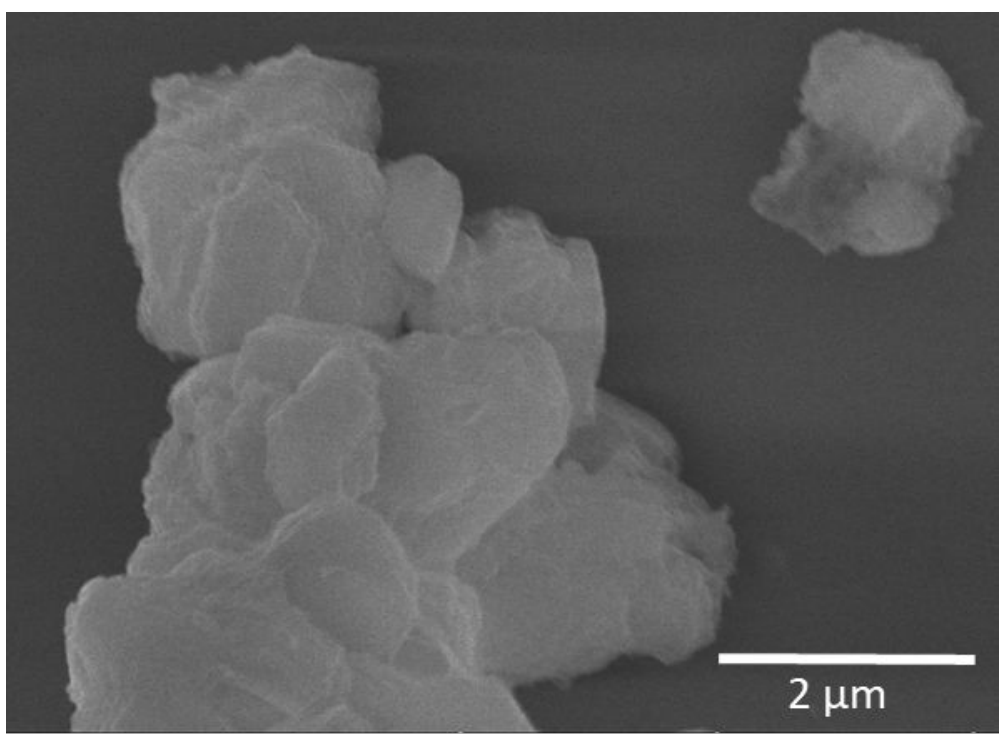

Figure S5. Low magnification SEM image of PMO-THEIC. 


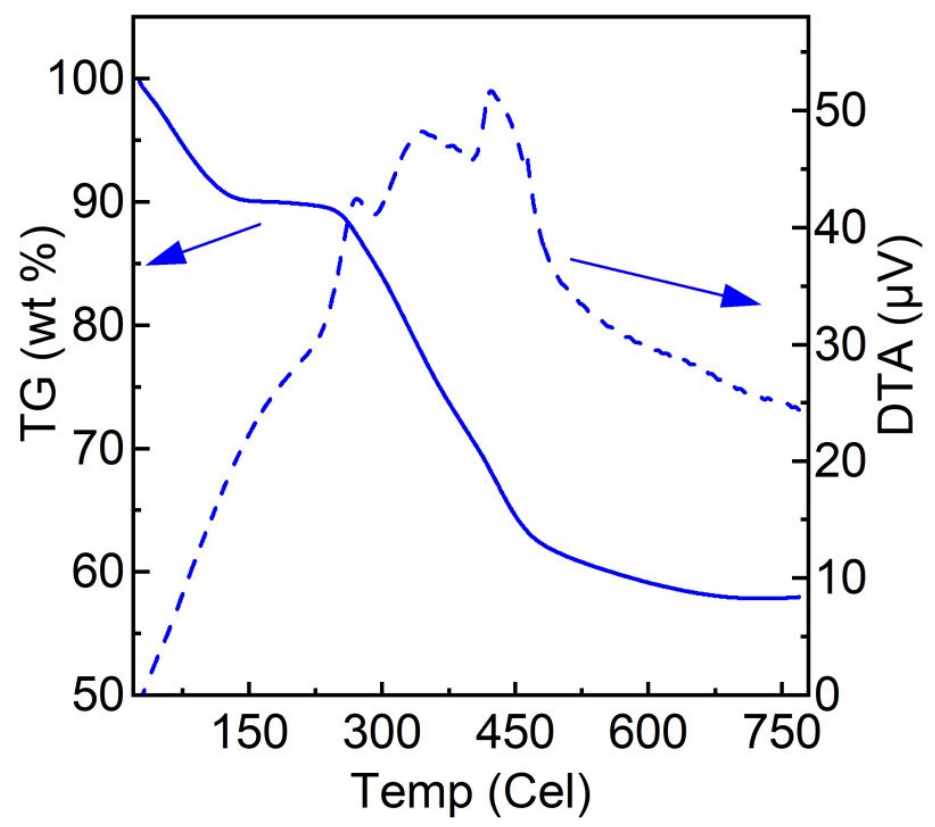

Figure S6. TG-DTA analysis of PMO-THEIC.

\section{Materials Characterization}

TG-DTA analysis of PMO-THEIC was recorded using a Rigaku Thermo plus TG8120 apparatus. XRD pattern was collected by a Rigaku X-ray diffractometer with $\mathrm{Cu} \mathrm{K} \alpha$ radiation at $30 \mathrm{KV}$ and $15 \mathrm{~mA}$. Fourier-transform infrared spectroscopy (FTIR) spectra were recorded on a Shimadzu FTIR-4200. The SEM images were observed with a HITACHI SU-8230 scanning SEM. TEM images were taken with a JEOL JEM-2100F microscope (operated at $300 \mathrm{kV}$ ). $\mathrm{N}_{2}$ adsorption/desorption and $\mathrm{BJH}$ analyses were carried out at $-196{ }^{\circ} \mathrm{C}$ using a Microtrac Bel BEL-mini. Before the measurements, the sample was evacuated at $90{ }^{\circ} \mathrm{C}$ for $20-24 \mathrm{~h} . \mathrm{CO}_{2}$ adsorption analyses were recorded by MicroActive for TriStar II Plus 2.03. ${ }^{1} \mathrm{H}-\mathrm{NMR}$ and ${ }^{13} \mathrm{C}-\mathrm{NMR}$ spectra were recorded by JEOL Delta 75 and $300 \mathrm{MHz}$ spectrometers, respectively. ${ }^{29} \mathrm{Si}$ magic-angle spinning (MAS) NMR spectra and ${ }^{13} \mathrm{C}$ cross-polarized (CP) MAS NMR spectra were recorded at $119.17 \mathrm{MHz}$ on a Varian 600PS solid-state NMR spectrometer using a $6 \mathrm{~mm}$ diameter zirconia rotor. 


\section{4. $\mathrm{CO}_{2}$ Tests Results}

The comparative results indicate that PMO-THEIC has $\sim 3$ folds higher $\mathrm{CO}_{2}$ capture capacity compared to SBA-15, which reveals that $\mathrm{CO}_{2}$ capture capacity has been enhanced three times once the bridge is embedded in the pore walls. Furthermore, the previously reported PMOs were compared with PMO-THEIC in Table S1. Although urea-bridged PMO, which also has a pyridine group in each molecule of the bridge, $\mathrm{CO}_{2}$ capture capacity is lower than that of PMO-THEIC. The only case in which its capacity is observed to be higher than that PMO-THEIC is a PMO that is post-modified with amine groups. This higher activity is because of the high tendency of amine group toward $\mathrm{CO}_{2}$ capture. However, the amine group is not stable in air and maybe oxidized in long term exposure to air oxygen.

Table S1. Comparison of previously published mesoporous materials with PMO-THEIC at $25^{\circ} \mathrm{C}$.

\begin{tabular}{|c|c|c|c|c|c|}
\hline Entry & Adsorbent & $\begin{array}{c}\text { BET surface } \\
\text { area } \\
\left(\mathrm{m}^{2} \mathrm{~g}^{-1}\right)\end{array}$ & $\begin{array}{l}\mathrm{CO}_{2} \text { adsorption } \\
(\mathrm{mmol} / \mathrm{g})\end{array}$ & Remarks & Ref. \\
\hline 1 & PMO-UDF-15 & 979 & 0.62 & $\begin{array}{l}\text { The bridge has two urea sites } \\
\text { with one pyridine core. }\end{array}$ & 14 \\
\hline 2 & ВРMO & 645 & 0.57 & The bridge is a benzene. & 15 \\
\hline 3 & A2-BPMO & 180 & 3.03 & $\begin{array}{l}\text { The PMO here is } \\
\text { postmodified with an amine } \\
\text { group }\end{array}$ & 15 \\
\hline 5 & PMO-DADD & 450 & 0.88 & $\begin{array}{l}\text { Every mole of bridge here } \\
\text { has four amine functions } \\
\text { with a long aliphatic chain }\end{array}$ & 16 \\
\hline 6 & SBA-15 & 650 & 0.4 & $\begin{array}{l}\text { This silica mesopore has no } \\
\text { functional group is as } \\
\text { reference sample }\end{array}$ & $\begin{array}{l}\text { This } \\
\text { work }\end{array}$ \\
\hline 4 & PMO-THEIC * & 697 & 1.1 & $\begin{array}{l}\text { it contains three carbamate } \\
\text { groups in each bridge which } \\
\text { is linked with isocyanurate } \\
\text { core }\end{array}$ & $\begin{array}{l}\text { This } \\
\text { work }\end{array}$ \\
\hline
\end{tabular}


The heat of adsorption $\left(\mathrm{Q}_{\mathrm{st}}\right)$ values were obtained for PMO-THEIC according to the adsorbed $\mathrm{CO}_{2}$ values obtained at two different temperatures $(273 \mathrm{~K}$ and $298 \mathrm{~K})$ and the $\mathrm{Q}_{\text {st }}$ was depicted as a function of the amounts of adsorbed $\mathrm{CO}_{2}$ into PMO-THEIC. The values of $\mathrm{Q}_{\text {st }}$ were obtained according to the standard method using the following equation:

$$
\ln \left(\frac{P 1}{P 2}\right)=\frac{Q_{s t}}{R}\left(\frac{1}{T_{2}}-\frac{1}{T_{1}}\right)
$$

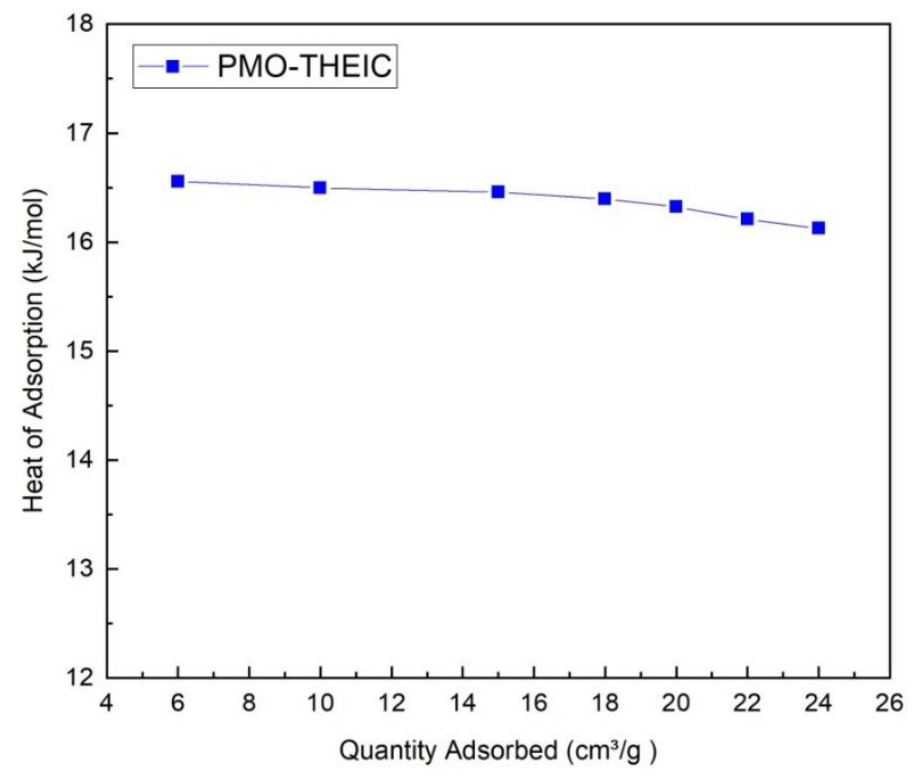

Figure S7. Heat of adsorption plot $\left(\mathrm{Q}_{\mathrm{st}}\right)$ for $\mathrm{CO}_{2}$ capture test in PMO-THEIC for different the amount of adsorbed $\mathrm{CO}_{2}$ at $273 \mathrm{~K}$ and $298 \mathrm{~K}$. 

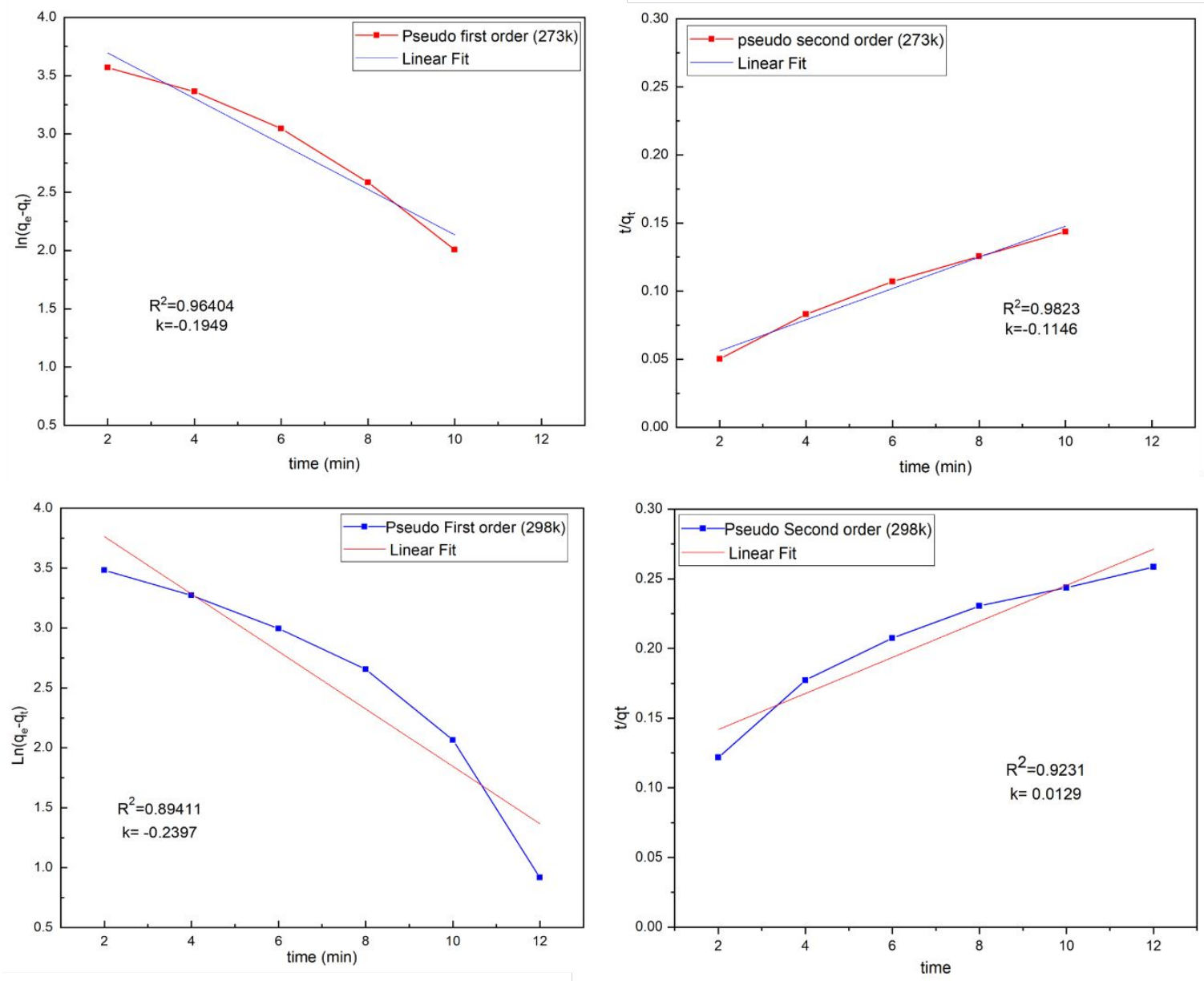

Figure S8. Pseudo-first-order kinetic plots of PMO-THEIC CO $\mathrm{CO}_{2}$ capture at a) $273 \mathrm{~K}$ and b) $298 \mathrm{~K}$. Pseudo-second-order kinetic plots of PMO-THEIC CO $\mathrm{CO}_{2}$ capture at a) $273 \mathrm{~K}$ and b) $298 \mathrm{~K}$.

\section{Density Functional Calculations}

Gamma-point density functional calculations were carried out within the framework of the projector augmented wave formalism ${ }^{1}$ with Perdew-Burke-Ernzerhof functional for general gradient approximation $(\mathrm{GGA})^{2,}{ }^{3}$ as implemented in the VASP code. ${ }^{4}$ The van der Waals interaction was taken into account based on Klimeš formalism. ${ }^{5,6}$ Since the DFT study was aimed at understanding the interaction between $\mathrm{CO}_{2}$ and THEIC bridge, we first optimized the THEIC structure capped with $\mathrm{Si}(\mathrm{OH})_{3}$ at each end to forces smaller than $0.05 \AA^{-1}$. The THEIC structure was placed in a large box of $30 \AA \times 30 \AA \times 30 \AA$, shown in the inset of Figure S9, to prevent THEIC structure from interacting with its own image created by the periodic boundary conditions. 
Capping large molecular units with $\mathrm{H}$, as employed here, has been proven the to be effective for economically simulating large molecules and structures. ${ }^{7,8}$

We then examined the interaction between $\mathrm{CO}_{2}$ molecule and the THEIC bridge. We fixed the position of the Si ions, and their accompanying $\mathrm{OH}$ groups, to simulate the attachment of the bridge to the inorganic $\mathrm{SiO}_{2}$ portion of the PMO. The fixed ions are marked with anchors in Figure S9. We then calculated the adsorption energy of the $\mathrm{CO}_{2}$ molecule onto different adsorption points on the THEIC structure. The adsorption energy $\left(E^{\mathrm{ad}}\right)$ was calculated as:

$$
E^{\mathrm{ad}}=E\left(\text { THEIC }+\mathrm{CO}_{2}\right)-E(\text { THEIC })-E\left(\mathrm{CO}_{2}\right) .
$$

Here, $E\left(\right.$ THEIC $\left.+\mathrm{CO}_{2}\right)$ is the total density functional energy of the THEIC bridge with $\mathrm{CO}_{2}$ molecule attached, E(THEIC) is the total density functional energy of the THEIC bridge studied in the previous section, and $E\left(\mathrm{CO}_{2}\right)$ is the total energy of the carbon dioxide molecule. Adsorption is stable only if $E^{\text {ad }}$ is negative. In total, five such adsorption points were considered, four of which were not stable. The unstable points are marked with starts in Figure S9. The only stable adsorption point was the configuration in which the $\mathrm{C}$ atom in the $\mathrm{CO}_{2}$ molecule bonded to the doubly bonded $\mathrm{O}$ atom of the THEIC arm. The adsorption energy, in this case, was $-0.467 \mathrm{eV}$. This adsorption energy was mainly driven by the van der Waals interaction. We quantified the role of the van der Waals interaction by repeating the simulation without the inclusion of the van der Waals termGGA only $-E^{\text {ad }}$ changed to $-0.103 \mathrm{eV}$, substantially less stable. Finally, to examine the stability structure at ambient, ${ }^{9}$ we ran a room temperature ab initio molecular dynamics simulations based on a micro-canonical ensemble with steps of $0.1 \mathrm{fs}$ for $10 \mathrm{ps}$. This adsorption point was stable as the $\mathrm{CO}_{2}$ molecule remained tightly bonded to the THEIC bridge.

We, therefore, demonstrated the significant role of the van der Waals interaction in binding the $\mathrm{CO}_{2}$ molecule to the THEIC bridge. Similarly, the van der Waals interaction has also been 
identified as a considerable contributing factor to the adsorption of $\mathrm{CO}_{2}$ to the organic part of many organic/inorganic systems and metal-organic frameworks. Here are some examples to mention a few: the adsorption of $\mathrm{CO}_{2}$ onto Mg-MOF74 and Ca-BTT, ${ }^{10}$ onto M/DOBDC $(\mathrm{M}=\mathrm{Mg}, \mathrm{Ni}, \mathrm{Co})$ and $\mathrm{Cu}$-HKUST- $1,{ }^{11}$ onto Siliceous MFI and DDR, ${ }^{12}$ and $\mathrm{C}_{3} \mathrm{~N} .{ }^{13}$

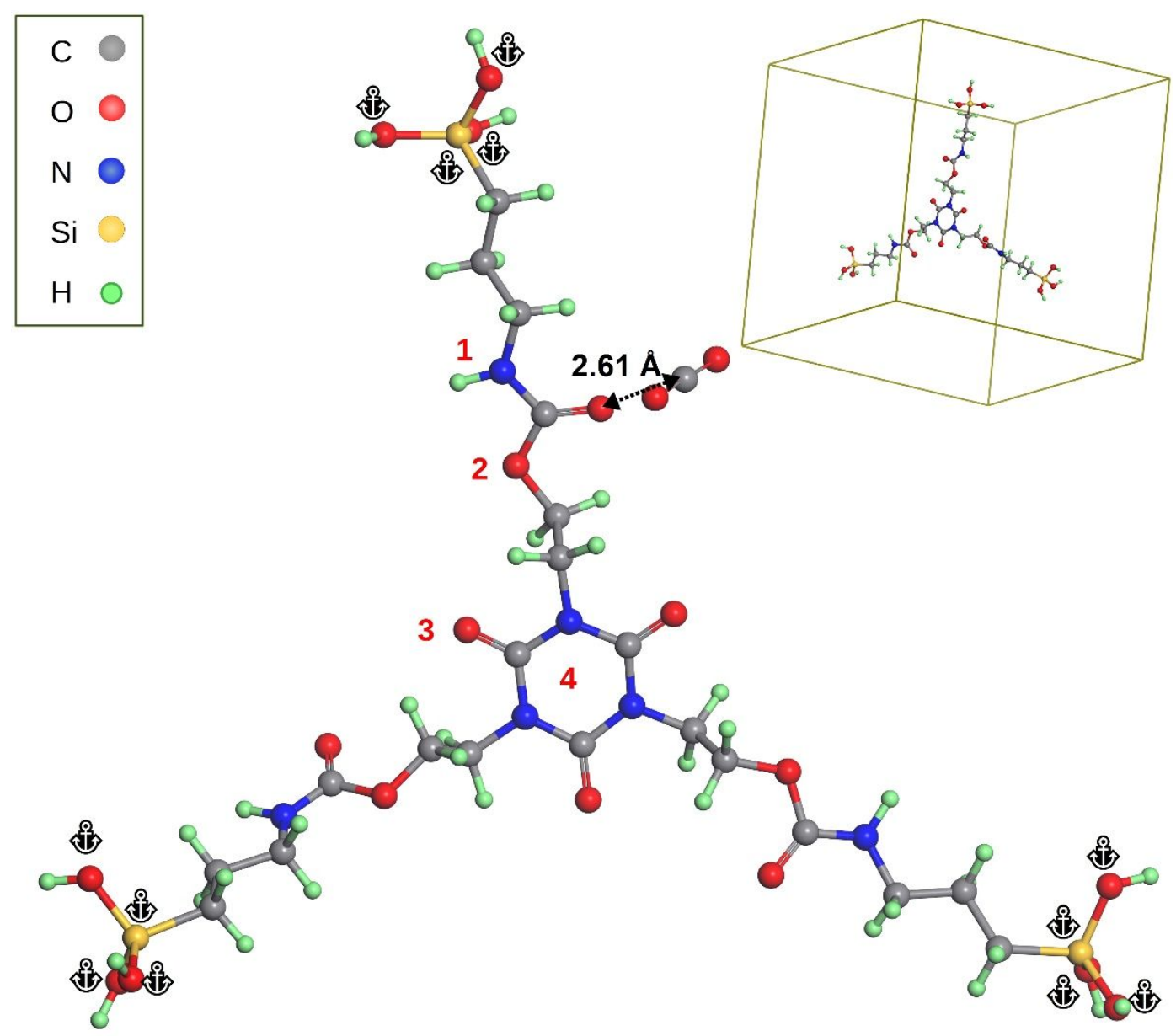

Figure S9. The schematic of the THEIC bridge anchored to $\mathrm{Si}(\mathrm{OH})_{3}$ terminals interacting with the $\mathrm{CO}_{2}$ molecule. The numbers in the figure represents the following atoms: $1=\mathrm{N}, 2=\mathrm{O}, 3=\mathrm{O}, 4=$ ring.

\section{Experimental section}

Synthesis of 1,3,5-tris(2-(3-(triethoxysilyl)propoxy)ethyl)-1,3,5-triazinane-2,4,6trione (THEIC bridge): For the synthesis of this organosiloxane bridge, THEIC ( $3 \mathrm{mmol}$, $0.783 \mathrm{~g}$ ) was added to (3-isocyanatopropyl)triethoxysilane $(1 \mathrm{mmol}, 0.5 \mathrm{~mL})$ in a glass vial, 
degassed with argon and stirred at $160{ }^{\circ} \mathrm{C}$ for $3 \mathrm{~h}$. Then, the temperature was reduced to $120^{\circ} \mathrm{C}$ and stirred for $6 \mathrm{~h}$. Finally, a colorless viscous liquid was collected as a product (it was named THEIC bridge) and used for the next step.

General procedure for the synthesis of PMO-THEIC: The synthesized THEIC bridge was employed in the synthesis of a new PMO. A Pluronic triblock copolymer P123, purchased from Sigma-Aldrich $\left(2 \mathrm{~g}, \mathrm{MW}=5800 \mathrm{~g} \cdot \mathrm{mol}^{-1}\right)$, was dissolved in $\mathrm{HCl}$ aqueous solution $\left(0.5 \times 10^{-1} \mathrm{M}, 75 \mathrm{~mL}\right)$ and stirred for $3 \mathrm{~h}$. Then, the as-synthesized THEIC organosiloxane bridge from the last step was mixed with TEOS with the molar ratio of $1: 15$, respectively, added to the $\mathrm{P} 123 / \mathrm{HCl}$ aqueous solution and stirred for $24 \mathrm{~h}$ at $25^{\circ} \mathrm{C}$ while the final $\mathrm{pH}$ was set at 5 . After $24 \mathrm{~h}$, the reaction mixture was transferred to the autoclave for aging for $24 \mathrm{~h}$ at $100{ }^{\circ} \mathrm{C}$. After aging, the structure-directing agent (SDA), P123, was extracted from the final product using Soxhlet with $\mathrm{MeOH}$ for 4 days. The final product was obtained after drying at $60^{\circ} \mathrm{C}$ for $4 \mathrm{~h}$ in an oven.

\section{References}

1. Kresse, G.; Joubert, D., From ultrasoft pseudopotentials to the projector augmented-wave method. Phys. Rev. B 1999, 59 (3), 1758-1775.

2. Perdew, J. P.; Burke, K.; Ernzerhof, M., Generalized Gradient Approximation Made Simple. Phys. Rev. Lett. 1996, 77 (18), 3865-3868.

3. Perdew, J. P.; Burke, K.; Ernzerhof, M., Generalized Gradient Approximation Made Simple [Phys. Rev. Lett. 77, 3865 (1996)]. Phys. Rev. Lett. 1997, 78 (7), 1396-1396.

4. Kresse, G.; Furthmüller, J., Efficiency of ab-initio total energy calculations for metals and semiconductors using a plane-wave basis set. Comput. Mater. Sci. 1996, 6 (1), 15-50.

5. Klimeš, J.; Bowler, D. R.; Michaelides, A., Chemical accuracy for the van der Waals density functional. J. Phys. Condens. Matter 2009, 22 (2), 022201.

6. Klimeš, J.; Bowler, D. R.; Michaelides, A., Van der Waals density functionals applied to solids. Phys. Rev. B 2011, 83 (19), 195131. 
7. Teunissen, E.; Van Duijneveldt, F.; Van Santen, R., Interaction of ammonia with a zeolitic proton: ab initio quantum-chemical cluster calculations. J. Phys. Chem. 1992, 96 (1), 366-371.

8. Salustro, S.; Ferrari, A. M.; Orlando, R.; Dovesi, R., Comparison between cluster and supercell approaches: the case of defects in diamond. Theor. Chem. Acc. 2017, 136 (4), 42.

9. Assadi, M. H. N.; Sahajwalla, V., Polymers' surface interactions with molten iron: A theoretical study. Chem. Phys. 2014, 443, 107-111.

10. Poloni, R.; Smit, B.; Neaton, J. B., $\mathrm{CO}_{2}$ capture by metal-organic frameworks with van der Waals density functionals. J. Phys. Chem. A 2012, 116 (20), 4957-4964.

11. Rana, M. K.; Koh, H. S.; Hwang, J.; Siegel, D. J., Comparing van der Waals density functionals for $\mathrm{CO}_{2}$ adsorption in metal organic frameworks. J. Phys. Chem. C 2012, 116 (32), 16957-16968.

12. Fang, H.; Kamakoti, P.; Zang, J.; Cundy, S.; Paur, C.; Ravikovitch, P. I.; Sholl, D. S., Prediction of $\mathrm{CO}_{2}$ adsorption properties in zeolites using force fields derived from periodic dispersion-corrected DFT calculations. J. Phys. Chem. C 2012, 116 (19), 10692-10701.

13. Li, X.; Zhu, L.; Xue, Q.; Chang, X.; Ling, C.; Xing, W., Superior selective $\mathrm{CO}_{2}$ adsorption of $\mathrm{C}_{3} \mathrm{~N}$ pores: GCMC and DFT simulations. ACS Appl. Mater. Interfaces 2017, 9 (36), 31161-31169.

14. Liu, M.; Lu, X.; Shi, L.; Wang, F.; Sun, J., Periodic Mesoporous Organosilica with a Basic UreaDerived Framework for Enhanced Carbon Dioxide Capture and Conversion Under Mild Conditions. ChemSusChem 2017, 10 (6), 1110-1119.

15. Sim, K.; Lee, N.; Kim, J.; Cho, E.-B.; Gunathilake, C.; Jaroniec, M., $\mathrm{CO}_{2}$ Adsorption on AmineFunctionalized Periodic Mesoporous Benzenesilicas. ACS Appl. Mater. Interfaces 2015, 7 (12), 6792-6802.

16. De Canck, E.; Ascoop, I.; Sayari, A.; Van Der Voort, P., Periodic mesoporous organosilicas functionalized with a wide variety of amines for $\mathrm{CO}_{2}$ adsorption. Phys. Chem. Chem. Phys. 2013, 15 (24), 9792-9799. 